\title{
TOWARD A COMPREHENSIVE DEFINITION OF THE NON-USER
}

\author{
L. Augustin ${ }^{凶}$, B. Kokoschko, M. Wiesner and M. Schabacker \\ Otto von Guericke University Magdeburg, Germany \\ $\bowtie$ laura.augustin@ovgu.de
}

\begin{abstract}
The user has been very well defined over the last decades. With human-centered design becoming more widely applied within various industries, the user's needs are being taken into account more than ever. What is often overlooked is the user's counterpart: the non-user. Integrating the non-user into modern development projects provides great additional value. This paper is compiling current definitions in order to analyse them within the context of product development and to make a contribution toward a comprehensive definition of the non-user that can be applied to various disciplines.
\end{abstract}

Keywords: user-centred design, non-user, industrial design, integrated product development, user integration

\section{Introduction}

Human-centred design has defined the user in various ways (Kurosu, 2011; Gardan, 2017) in order to make products or services more useful, successful or sustainable. Product development uses a wide variety of tools in order to integrate the user earlier and more extensively, as seen with user/customer journeys (Lemon and Verhoef, 2016), personas (Nielsen et al., 2015) and many more. But the user only makes up one side of the spectrum, while with most products, the non-user occupies at least the same amount of space if not more.

"Non-use is not an absence or a gap; it is not negative space. Non-use is, often, active, meaningful, motivated, considered, structured, specific, nuanced, directed, and productive." (Satchell and Dourish, 2009)

This contribution is seeking to compile, analyse and evaluate a wide range of definitions of the non-user from different fields of research by reviewing current literature. The goal is to form a comprehensive set of definitions, that can be applied in various disciplines in order to include the non-user when discussing use in a human-centred approach.

\section{Literature research approach}

This section gives a general overview over the reviewing process before discussing the detailed findings in section 3 .

The tool used for the search was Google Scholar and search terms used were centred around the non-user, i.e.: non-user, user, non-use, non-customer and user-centred in both spelling with and without the hyphen. 
The two main re quirements for literature to be deemed relevant were:

- Literature cannot only contain case-specific descriptions of non-use (i.e. "How many people are not using xyz").

- Authors have to address or define categories of non-use or non-users.

The most relevant literature found can be divided into three categories, as described in section 3 .

\section{Overview of current definitions of the non-user}

Many different disciplines have defined the non-user from their unique perspective. This section gives an overview over three of them: product development, marketing and social sciences.

\subsection{The non-user in product development}

Most established literature in product development includes the user (Ehrlenspiel et al., 2007; Feldhusen and Grote, 2013; Lindemann, 2007) and several stakeholders (Feldhusen and Grote, 2013; Vajna, 2014; Urakami and Vajna, 2018), but a clear definition of non-users is missing.

Figure 1 describes all parties involved in the development process according to Integrated Design Engineering following Vajna (2014), starting with providers such as the product developer, manufacturer, supplier or distributor. Upon market entrance, whole salers, distributors, agents and retailers move the product or service to the next group of stakeholders, mainly the user, the buyer and then consequently, the group affected/disturbed.
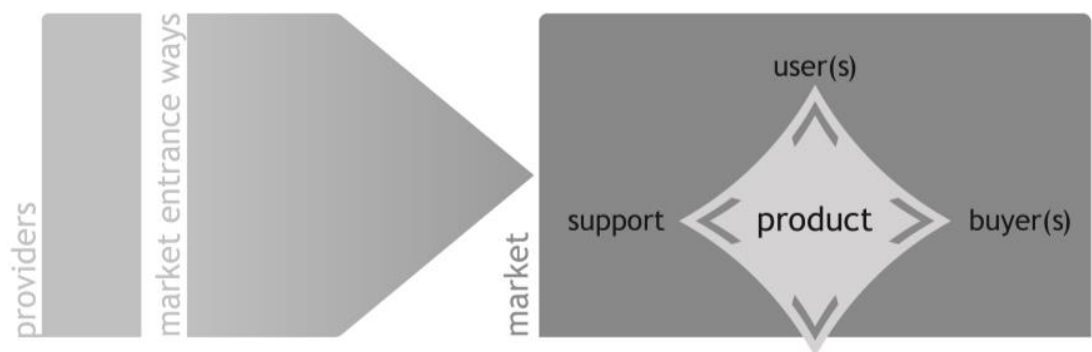

people affected

Figure 1. Stakeholders in product development (based on Vajna, 2014)

The only non-user in Figure 1 refers to is the person or group affected/disturbed, which describes only a small portion of non-users, namely the ones in direct contact with users, who are negatively affected, as the word implies. The underlying insinuation is: the group has to be "annoyed" with the outcome, the only group worth considering is the group of non-users that directly or indirectly interacts with the users.

However, the group of non-users is substantially bigger, as illustrated in the following sections.

\subsection{Noncustomers in marketing}

In marketing the term most frequently used is the noncustomer, differentiating only between people who buy the product or who don't. The customer cannot be generally equated with the user of course, since these two can (but don't have to) be different entities. In the context of this paper, however, the term of the noncustomer and its different classifications can be used as valuable input in order to better define the non-user.

The lost customer analysis (Barsch et al., 2019) as well as the model describing the diffusion of innovation (Rogers, 1983) is discussed in the following paragraphs, giving an overview of two of the most influential pieces of research in marketing.

\subsubsection{Lost customer analysis (Blue Ocean Strategy)}

The lost customer analysis describes a three-tier model of non-customers (Barsch et al., 2019), divided into soon-to-be, refusing and unexplored customers, as shown in Figure 2. 


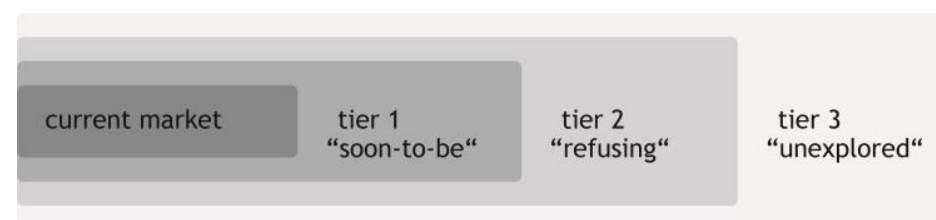

Figure 2. Lost customer analysis (based on Kim and Mauborgne, 2015, p. 106)

The soon-to-be noncustomers are the only group still using the product in question, but who are about to stop using it. The refusing noncustomers are actively resisting the product group in general, using for example a completely different type of product. The unexplored noncustomers are part of a completely different market and therefore seemed irrelevant so far.

This model rightly visualises the importance of exploring outside of the usual user group in order to immensely increase a product's market potential. If all groups can be addressed, in addition to the current market, more people will be addressed. Noncustomers can be turned into a target audience, if addressed correctly.

An often mentioned example of this approach is the company "Dollar Shave Club" and its success (Pasquier, 2013). They applied the lost customer analysis to customers and noncustomers of razors:

a) soon-to-be non-customers (dissatisfied razors users)

b) refusing customers (dry shave users)

c) unexplored non-customers (occasional shavers, barber shop goers)

By including all of these three groups in their innovation process and business model building, they were able to reach a completely new set of customers, who were not part of the original market before (Pasquier, 2013).

Nevertheless, the lost customer analysis is still vague in the sense that tier two and three are a very large and still relatively undefined group for it to be used in any development project. Both can be divided into subdivisions, clarifying types of refusal (tier two) or types of markets and their distance to the current market (tier three).

\subsubsection{Diffusion of innovation and laggards}

Roger's well known bell curve in Figure 3 (Rogers, 1983) describes the diffusion of innovation. Starting with innovators and early adopters, who adopt technology early on, followed by the early and late majority. The last part of the diffusion bell are the laggards, the last group to adopt an innovation.

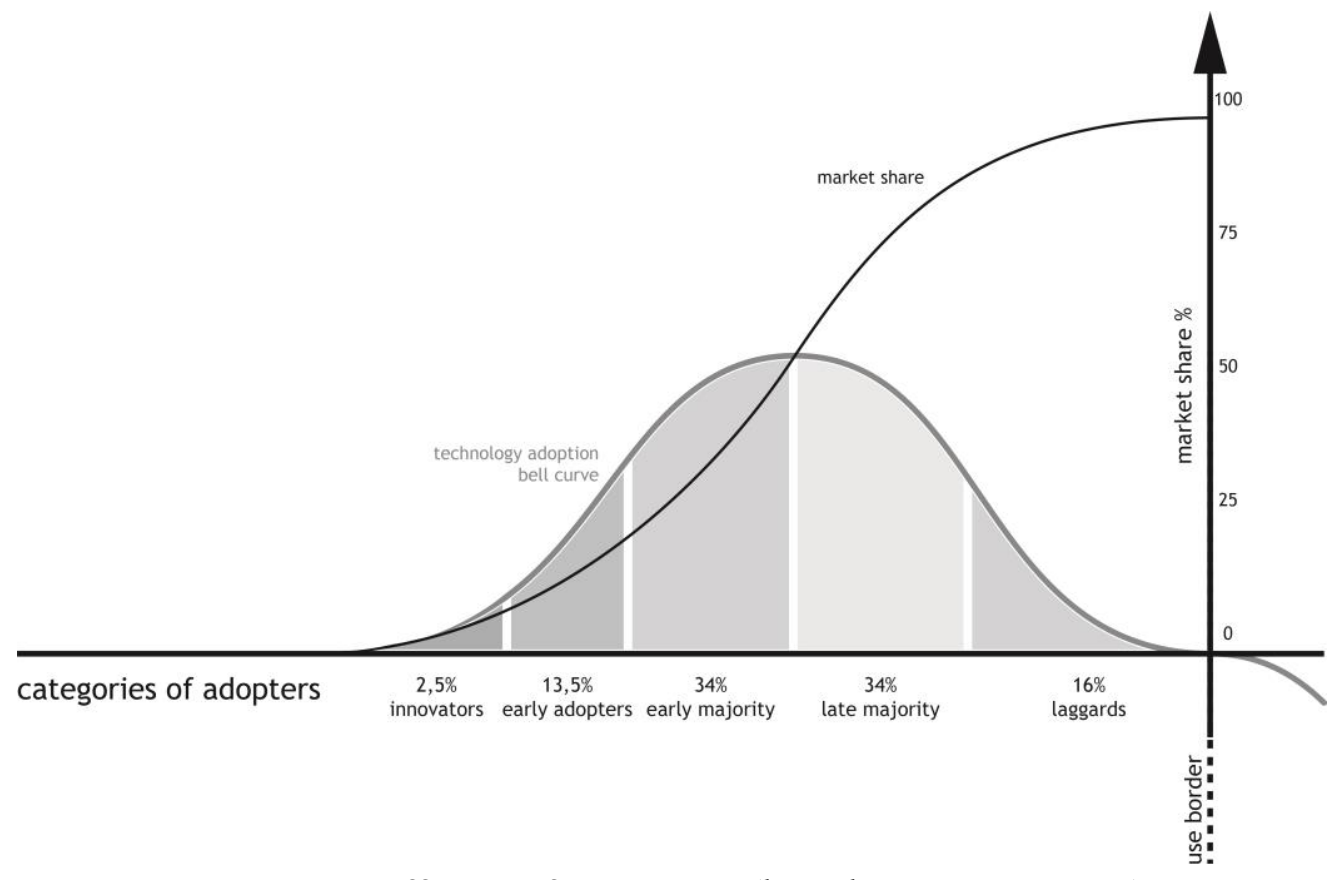

Figure 3. Diffusion of innovation (based on Rogers, 1983) 
The concept of late adopters, or laggards, is useful to include in the definition of the different types of non-users, as they pose as the opposition to the soon-to-be noncustomers from the lost customer analysis that was just discussed. One is slowly adopting a technology and one is slowly leaving the market or just about to. It can be beneficial to analyse both in order to ask why they are late to an innovation or not convinced enough to keep using it.

\subsection{The non-user in social sciences}

The last field of relevant research defining non-use can be identified as social sciences and their thorough work on non-users. This passage is organised according to the type of definition made, starting with the relationship between adoption and non-adoption.

\subsubsection{Adoption and non-adoption as a complex relationship}

Marketing has presumed the relationship of adoption and non-adoption to be of a rather linear kind (Patsiotis et al., 2013). Seen as opposite sides of a spectrum, they are merely mirroring each other, not leaving the possibility of completely different types of non-adoption other than "reasons for adoption were not strong enough". Suzuki and Williams (1998) brought in the term "lack of need" of the technology as a type of non-adoption. Indifference or lack of awareness is described as passive resistance (Patsiotis et al., 2013), suggesting that non-adoption can be divided into different types and levels of resistance (Patsiotis et al., 2013).

Bauer (1995, p. 14-15) also used the terms active and passive resistance to describe non-adoption. The definition is divided into two pairs, active/passive and individual/collective (1995, p. 16).

\subsubsection{Degrees of non-acceptance and the space between use and non-use}

Miles and Thomas (1995, p. 256f) define non-acceptance in five levels of resistance, distinguishing between non-use of a technological system as a whole and specific aspects of it, i.e. not using all functions of a technology.

Figure 4 depicts the different levels of resistance towards interactive products, the first level describing the use of only one specific feature of a product, while not being interested in learning about other possible features, therefore resisting parts of the product. Level 2 means refusing to use a specific interface and only using a particular product design. In level 3 the user is applying a class of technology to a type of application, for example refusing to use a personal computer to store personal data due to safety concerns. Level 4 is avoiding a certain class of technology, while accepting that others might use it. Level 5 however means that no use at all is possible due to a principled resistance of the non-user (Miles and Thomas, 1995).

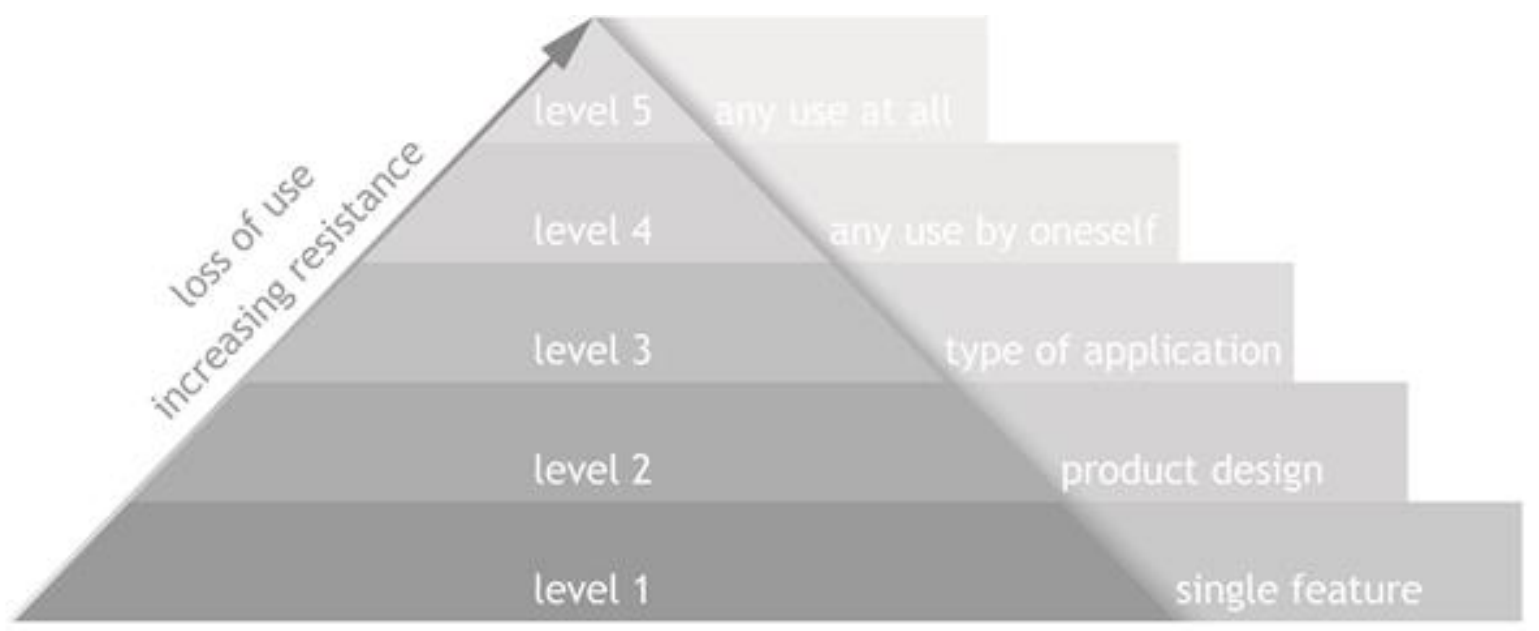

user resistance levels

Figure 4. Levels of resistance (based on Miles and Thomas, 1995) 
The segmentation of non-acceptance into the amount of aspects that are rejected is an intriguing approach, that makes an important differentiation of degrees of rejection by breaking down a product into its features and interfaces.

Another important point made in this paper is the introduction of the term bewilderment (Miles and Thomas, 1995, P. 257), describing the non-user's issue with deciding on what to choose due to for example range of choice or complexity of choice. This aspect of resistance or rejection is often overlooked and therefore an important aspect to consider, since this non-user might be fairly close to becoming a user. The term ambivalence may also be used to describe non-users' behaviour when choosing (or not choosing) a product or service (Ribak and Rosenthal, 2015), further adding substance to the rather undefined space between the user and the non-user.

Users might also only choose a product unwillingly or use it rarely (Miles and Thomas, 1995, p. 256), opening the discussion to types of use that marginally intersect with non-use.

\subsubsection{Forms of non-use derived from Roger's diffusion theory}

As pointed out earlier, Roger's diffusion theory assumes everyone to be users, defined by how early or late they adopt an innovation. Satchell and Dourish (2009) use Roger's theory in order to expand it and use the "lagging adopters" as a starting point for their research, showing an overlap of users and non-users. Figure 5 is showing this overlap and allocates their definitions to non-users, who might easily become users and non-users, who are lost.

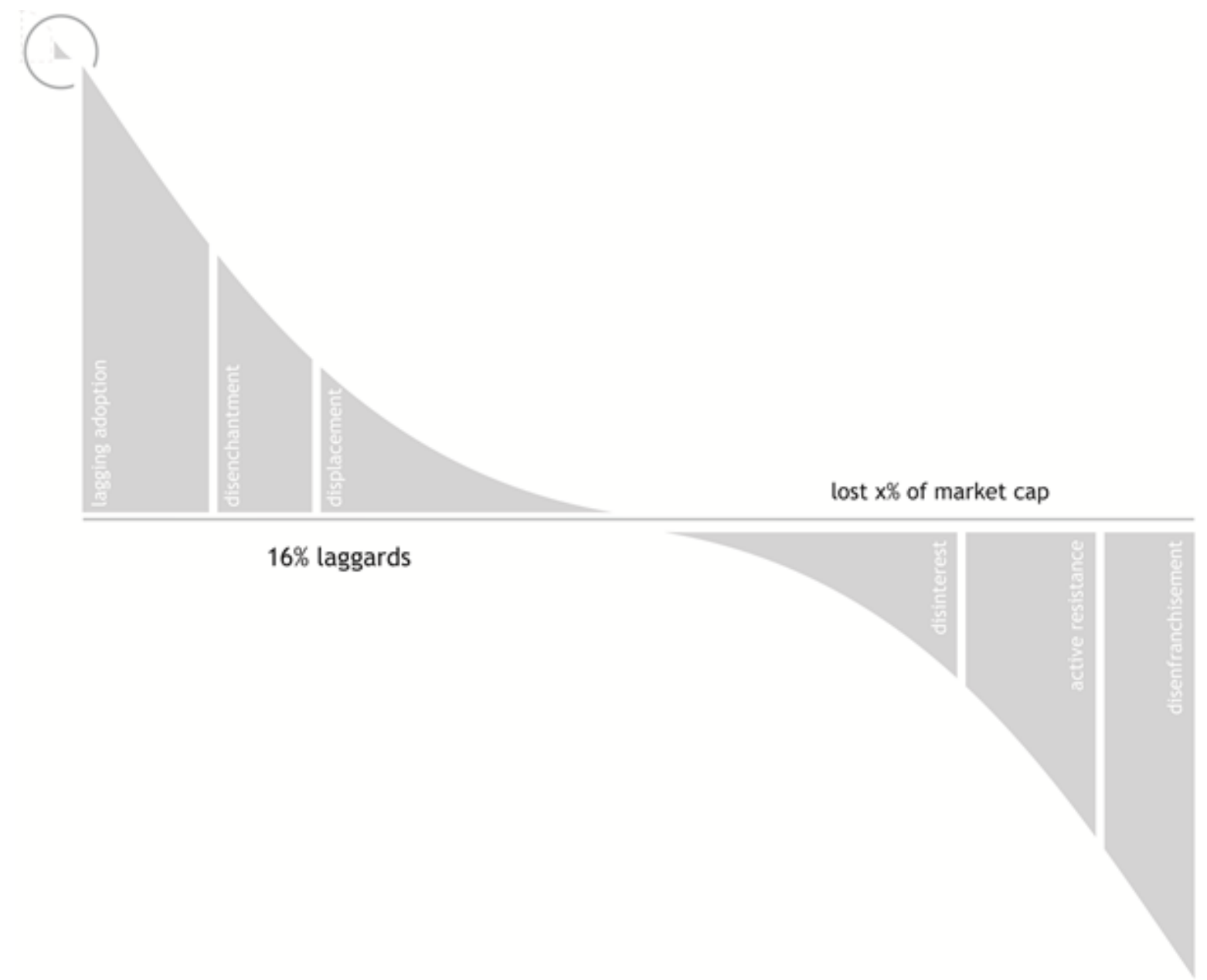

Figure 5. Laggards and lost market (based on Satchell and Dourish, 2009)

However, this set of definitions mixes two things: the type of non-use and the reasons for non-use. These need to be examined independently, starting with the type of non-use. The reasons for non-use might differ 
from industry to industry or even within the same product group, especially concerning the term disenchantment (non-use explained by nostalgic reasons), which is almost too specific for some to use.

The other types of non-use are lagging adoption (temporary non-use), displacement (non-use due to the fact that the product or service is already owned by someone in the household), disinterest, active resistance and disenfranchisement (lack of availability).

Figure 6 ranks the different categories according to the level of resistance.

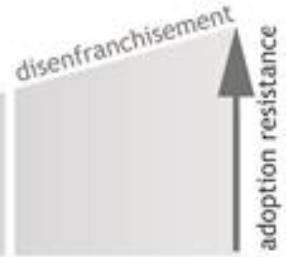

Figure 6. Forms of non-use (based on Satchell and Dourish, 2009)

The term displacement adds another level of non-use, that hasn't been very thoroughly researched before and shall be analysed further, especially since it is not clear, if the non-user of this type is accessing the product or service at all or via other household members or not at all.

Another aspect relevant to this model is the term "lagging resistance" (Hiniker et al., 2016), adding another dimension to users, who are about to become non-users.

\subsubsection{The resisters, rejecters, excluded and the expelled}

In an early taxonomy of non-users, four types of non-user are identified, as shown in Figure 7 (Wyatt, 2003). The resisters have never used something, because they don't want to and the rejecters have used something, but stopped using it voluntarily (Wyatt, 2003). Both can be classified as active resistance, as it has been a conscious choice.

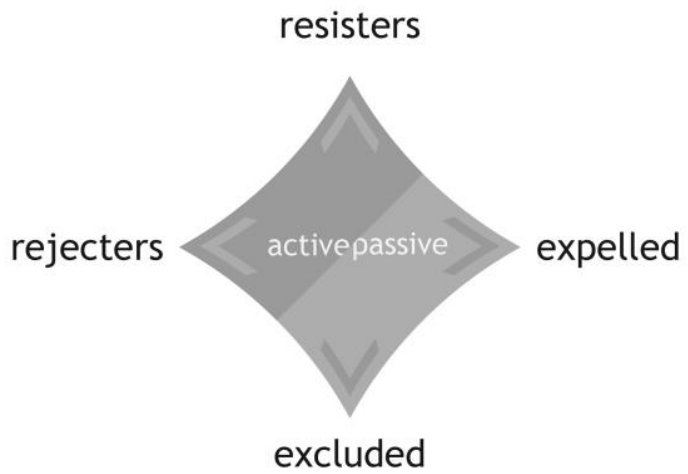

Figure 7. Four types of non-users (based on Wyatt, 2003)

The excluded have never used something due to no access, this can be for example socially or technically and the expelled have stopped using something involuntarily due to cost or loss of access (Wyatt, 2003). These two can be categorised as passive, since in contrary to the first two, their non-use was involuntary. The rejecters are still a fairly large non-user group and going forward it may be useful to define them in a more detailed manner. The excluded and the expelled are both rather specific in the context of non-user definitions and open up an interesting aspect of non-use: the field of the users who might like to use a product or service but cannot, due to varying reasons.

\subsection{The need for a new definition of non-users based on the current literature}

The extent and level of detail of definitions varies greatly between disciplines. In the following it is shown why none of these are fully sufficient:

- Product development is defining the group of stakeholders, but not exploring the non-user any further than "the group affected", which leaves out most non-users. 
- Marketing defines the noncustomer in three large and rather general tiers, while Roger's diffusion bell curve seems to deny the existence of a non-user altogether, therefore leaving a gap to be explored.

- The varying definitions in social sciences give the greatest overview and open the discussion to a number of definition types, which are classified in relation to the extent of resistance and active and passive resistance. However, reasons for non-use and types of non-use are mixed up in some definitions and are in need of a more precise differentiation.

- All definitions discussed in this paper are either very specific (or rather too specific to apply generally) or very vague and therefore not easily applicable. Most importantly, none of them allow for a certain movement or for fluent transitions between definitions, which is very much needed in the case of the non-user, who for example might be just about to stop using a product or service or in between wanting to use it and not wanting to.

In order to give a broad overview of non-users, their resistance to a product or service and whether they are using it voluntarily or not, a new definition map needs to be established.

\section{Mapping out a comprehensive definition of the non-user}

In order to translate the previous research into one set of applicable definitions, this section is discussing a non-user map, combining different definitions and adding some missing pieces while giving examples of how the non-user may be applied to development projects in the future.

In order to make the different definitions of the non-user more applicable, the non-user map was created. It combines an array of the most useful definitions discussed in this paper, with additions made. This map in Figure 8 is defined by two axes, one spanning the distance from someone wanting to use a product or service to not wanting to use it. The y-axis is divided into four areas, depending on the level of experience with a product or service and whether it is currently being used. The four areas are currently using, might use in the future, have used in the past but is currently not using and lastly the group of people who have never used the product or service in question. The darker the grey, the more the product or service is used.

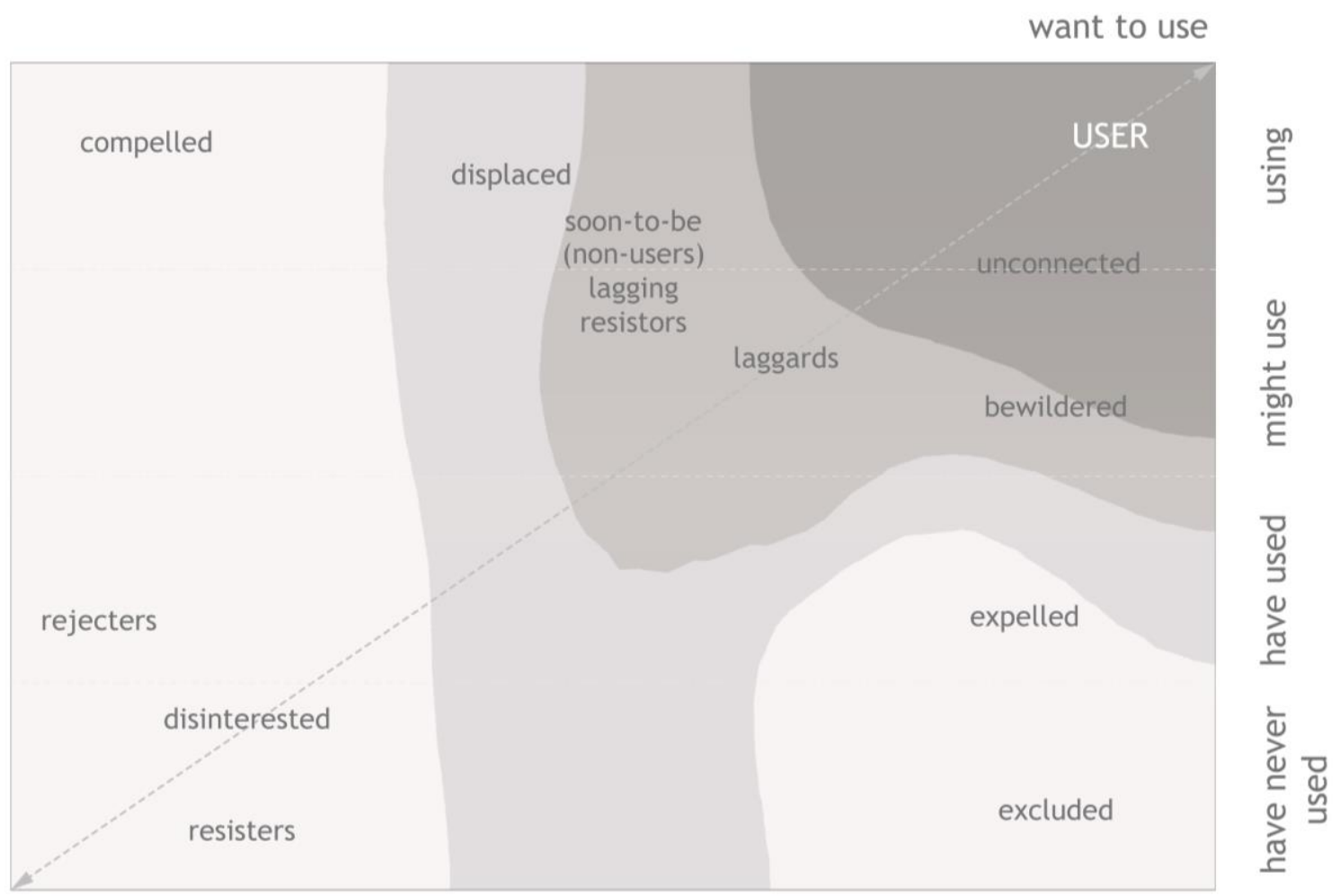

do not want to use

Figure 8. Non-user map 
In addition to the definitions discussed previously, new non-user types have been added in order to give a more detailed set of definitions. Starting on the top right, working down to the bottom left:

- the unconnected (users of a competitor's product, therefore using the product in general but not the one in question)

- the bewildered (confused by choice and therefore still non-users)

- the compelled (using a product out of necessity).

This graph is still a work in progress and will be adapted and added to as the project goes on.

\section{Summary}

The non-user and noncustomer have been researched in different disciplines over the last decades, with social sciences adding a great deal of detail to current literature. However, there is still a gap concerning a comprehensive set of definitions, while still leaving room for a certain fuzziness regarding non-users and their intent.

This contribution has compiled, analysed and summarised the most important insights from product development, marketing and social sciences, resulting in a comprehensive non-user map. This map gives an overview over the different types of users and non-users and visualises the grey areas in between. In order to give an example of how this new knowledge can be applied, the concept of a non-persona has been developed, visualising one possible implementation of the non-user into the development process.

\section{Outlook}

While this contribution illustrates the need and use for a comprehensive definition of the non-user, more research needs to be done. The non-user map will be extended and specified by further research and field tests in various development projects, both of which will be realised within this research project.

It is assumed that the findings can be integrated into product development with little effort by applying well-known methods such as the persona. For this purpose, an extended persona definition must be developed, which enables developers to visualise the different non-user properties and make them accessible to the development team. This persona definition will then have to prove itself in several case studies. Compared to the known persona definition, it shall at least address the aspects of the rejection level, the existing intention of use and the categorisation of use (currently using, possibly using, used and never used) as well as possible disabilities.

An additional literature review will be made expanding to more industries outside of product development, marketing and social sciences, in order to add to the current set of definitions. Furthermore, it is of utmost importance to apply the tools developed to a wide array of industries, to test its comprehensiveness and advance the concept of the non-user.

\section{References}

Barsch, T., Heupel, T. and Trautmann, H. (Ed.) (2019), The Blue Ocean Strategy in Theory and Practice, Springer Fachmedien Wiesbaden, Wiesbaden.

Bauer, M. (1995), "Resistance to new technology and its effects on nuclear power, information technology and biotechnology", In: Bauer, M. (Ed.), Resistance to new technology, Cambridge University Press, Cambridge, pp. 1-41.

Cooper, A. (2004), The Inmates Are Running the Asylum. Why High-Tech Products Drive Us Crazy and How to Restore the Sanity, 2nd edition, Sams.

Ehrlenspiel, K. et al. (2007), Develop and construct inexpensively. Cost management in integrated product development. 6th, revised and corrected edition, Springer-Verlag Berlin Heidelberg (VDI-Book), Berlin, Heidelberg. http://doi.org/10.1007/978-3-540-74223-4

Feldhusen, J. and Grote, K.-H. (2013), Pahl/Beitz construction theory, Springer Berlin Heidelberg, Berlin, Heidelberg. https://doi.org/10.1007/978-1-4471-3581-4

Foth, M. (Ed.) (2009), "Proceedings of the 21st Annual Conference of the Australian Computer-Human Interaction Special Interest Group (CHISIG) of the Human Factors and Ergonomics Society of Australia 
(HFESA)", The 21st Annual Conference of the Australian Computer-Human Interaction Special Interest Group. Melbourne, Australia, 11/23/2009 - 11/27/2009. The University of Melbourne, ACM, New York.

Gardan, J. (2017), "Definition of users' requirements in the customized product design through a user-centered translation method", Int J Interact Des Manuf, Vol. 11 No. 4, pp. 813-821. https://doi.org/10.1007/s12008015-0275-2.

Hiniker, A. et al. (2016), "MyTime. Designing and Evaluating an Intervention for Smartphone Non-Use", In: Kaye, J. et al. (Ed.), Proceedings of the 34th Annual CHI Conference on Human Factors in Computing Systems. the 2016 CHI Conference. Santa Clara, California, USA, 5/7/2016 - 5/12/2016. CHI; Association for Computing Machinery; Annual CHI Conference on Human Factors in Computing Systems, The Association for Computing Machinery, New York, New York, pp. 4746-4757.

Kim, C. and Mauborgne, A. (2015), Blue Ocean Strategy, Expanded Edition: How to Create Uncontested Market Space and Make the Competition Irrelevant, Harvard Business Review Press, Boston Massachusetts, p. 105, ISBN: 9781625274496

Kurosu, M. (2011), Human Centered Design, Springer Berlin Heidelberg (6776), Berlin, Heidelberg.

Lemon, K.N. and Verhoef, P.C. (2016), "Understanding Customer Experience Throughout the Customer Journey”, Journal of Marketing, Vol. 80 No. 6, pp. 69-96. https://dx.doi.org/10.1509/jm.15.0420

Lindemann, U. (2007), Methodical development of technical products. Apply methods flexibly and according to the situation. 2nd edited edition. Springer-Verlag Berlin Heidelberg (VDI book), Berlin, Heidelberg, Online retrieved from http://doi.org/10.1007/978-3-540-37451-0

Miles, I. and Thomas, G. (1995), "User resistance to new interactive media: participants, processes and paradigms”, In: Bauer, M. (Ed.), Resistance to new technology. Cambridge University Press, Cambridge, pp. 255-275.

Nielsen, L. (2019), Personas - User Focused Design. 2nd ed., 2019. Springer London (Human-Computer Interaction Series), London, Online retrieved from http://doi.org/10.1007/978-1-4471-7427-1

Nielsen, L. et al. (2015), "A Template for Design Personas”, International Journal of Sociotechnology and Knowledge Development, Vol. 7 No. 1, pp. 45-61. https://dx.doi.org/10.4018/ijskd.2015010104.

Oudshoorn, N. and Pinch, Trevor J. (Ed.) (2003), How users matter. The co-construction of users and technologies. MIT Press (Inside technology), Cambridge, Mass.

Pasquier, M. (2013), Getting rid of competition and convincing non-customers with Blue Ocean Strategy. Available online at: https://www.innovationiseverywhere.com/getting-rid-competition-convincing-noncustomers-blue-ocean-strategy/, accessed 21.11.2019.

Patsiotis, A.G., Hughes, T. and Webber, D.J. (2013), “An examination of consumers' resistance to computerbased technologies”, Journal of Services Marketing 2013, Vol. 27 No. 4, pp. 294-311. https://doi.org/ $10.1108 / 08876041311330771$

Ribak, R. and Rosenthal, M. (2015), “Smartphone resistance as media ambivalence”, In: First Monday, Vol. 20, p. 11. https://dx.doi.org/10.5210/fm.v20i11.6307

Rogers, E.M. (1983), Diffusion of innovations, 3rd ed., Free Press; Collier Macmillan, New York, London.

Satchell, C. and Dourish, P. (2009), "Beyond the user: Use and non-use in HCI", In: M. Foth (Ed.), Proceedings of the 21st Annual Conference of the Australian Computer-Human Interaction Special Interest Group (CHISIG) of the Human Factors and Ergonomics Society of Australia (HFESA). Melbourne, Australia, 11/23/2009 - 11/27/2009. The University of Melbourne, ACM, New York, p. 9.

Urakami, J. and Vajna, S. (2018), "Human Centricity in Integrated Design Engineering”, In: Marjanović D. et al. (Ed.), Proceedings of the DESIGN 2018 15th International Design Conference, pp. 679-690.

Vajna, S. (Ed.) (2014), Integrated Design Engineering. Springer Berlin Heidelberg, Berlin, Heidelberg.

Wyatt, S. (2003), "Non-users also matter: The construction of users and non-users of the Internetm", In: Oudshoorn, N. and Trevor J. Pinch (Ed.), How users matter. The co-construction of users and technologies. Cambridge, MIT Press (Inside technology), Mass, pp. 67-80. 
